\title{
Laser patterning of thermoelectric iron silicide on alumina substrates by continuous-wave ytterbium fiber laser irradiation
}

\author{
Osaka Municipal Technical Research Institute, Electronic Materials Research Division, \\ 1-6-50 Morinomiya, Joto-ku, Osaka 536-8553, Japan \\ *Department of Applied Chemistry, Faculty of Science and Engineering, Kinki University, \\ 3-4-1 Kowakae, Higashi-Osaka, Osaka 577-8502, Japan
}

Hiroyasu KIDO, ${ }^{\dagger}$ Masanari TAKAHASHI, Jun-ichi TANI, Yoshinori SAWAIRI* and Mitsunobu IWASAKI*

\begin{abstract}
Patterns of the thermoelectric iron silicide were fabricated on alumina substrates with a continuous-wave ytterbium fiber laser. The laser irradiation process was further examined to construct an iron silicide device without damaging the substrates upon thermal shock. The multi-step irradiation process of powder mounting and irradiation demonstrated its performance as a thermoelectric device. Furthermore, the mechanism associated with the formation of an iron silicide layer was discussed. (C2014 The Ceramic Society of Japan. All rights reserved.
\end{abstract}

Key-words : Laser patterning, Yb-fiber laser, Iron silicide, Multi-step irradiation, Thermoelectric device

[Received May 12, 2014; Accepted June 24, 2014]

\section{Introduction}

Beta-phase iron disilicide $\left(\beta-\mathrm{FeSi}_{2}\right)$ has been extensively studied as a thermoelectric semiconductor material. ${ }^{1-3)} \beta-\mathrm{FeSi}_{2}$ is a promising material for applications owing to its thermoelectric and semiconducting properties. Structurally, the iron disilicide possesses a metallic $\alpha-\mathrm{FeSi}_{2}$ phase with an excess of silicon than the stoichiometric ratio and a semiconducting $\beta$ $\mathrm{FeSi}_{2}$ phase with stoichiometric composition. $\left.{ }^{4}\right) \mathrm{The} \beta-\mathrm{FeSi}_{2}$ is an intrinsic semiconductor with a band-gap of $0.87 \mathrm{eV}$, which exhibits a high absorption coefficient $\left(>10^{5} \mathrm{~cm}^{-1}\right.$ within the infrared region). ${ }^{5)}$ For the $\beta-\mathrm{FeSi}_{2}$ structure, an amorphous phase has also been reported. $\left.{ }^{6}\right)$ Moreover, the $\beta-\mathrm{FeSi}_{2}$ is capable of changing its conduction type when a portion of iron atoms are replaced by other transition metal atoms, i.e., the $\mathrm{Fe}_{1-x} \mathrm{Mn}_{x} \mathrm{Si}_{2}$ is a p-type semiconductor, ${ }^{7)}$ whereas $\mathrm{Fe}_{1-x} \mathrm{Co}_{x} \mathrm{Si}_{2}$ is an n-type semiconductor. $^{8)}$

The preparation and sintering of $\beta-\mathrm{FeSi}_{2}$ has previously been conducted by a range of methods, such as powder metallurgy and melting, ${ }^{9)}$ sputtering, ${ }^{10)}$ spark plasma sintering, ${ }^{11)}$ and YAG-laser sintering. ${ }^{12)}$ In recent years, an infrared Yb-fiber laser $(\lambda=$ $1070 \mathrm{~nm}$ ) has been developed for industrial level usage. It has higher energy conversion efficiency $(>30 \%)$ and higher beam quality $\left(\mathrm{M}^{2} \approx 1.0\right)$ than YAG or $\mathrm{CO}_{2}$ lasers. Previously, the $\mathrm{Yb}$ fiber laser was successfully employed in the growth of crystals in glasses, ${ }^{13), 14)}$ the surface densification of porous $\mathrm{ZrC},{ }^{15}$ ) the synthesis of $\mathrm{TiO}_{2}$ nanoparticles, ${ }^{16)}$ and the modification of electric properties of $\mathrm{ZnO}^{17)}$ and $\mathrm{TiO}_{2}{ }^{18)}$

In this study, we report on the fabrication of iron silicide devices using a continuous-wave $(\mathrm{CW}) \mathrm{Yb}$-fiber laser. This process offers a reduced thermal stress in the device to overcome the physical damage of substrates when subjected to thermal shock. Additionally, as the device is electro-conductive, it permits its use as a thermoelectric device. Moreover, the formation mechanism of the iron silicide layer on an alumina substrate is discussed. To the best of our knowledge, this is the first study reporting the use of

Corresponding author: H. Kido; E-mail: kido@omtri.or.jp
Yb-fiber irradiation for the fabrication of an iron silicide p-n device based on an alumina substrate.

\section{Experimental procedure}

The iron silicides were prepared by heating a mixture of $\mathrm{Fe}, \mathrm{Si}$, Mn, and Co powders (Kojundo Chemicals Laboratory Co., Ltd., purity: $99.9 \%$ for $\mathrm{Fe}, \mathrm{Mn}, \mathrm{Si}$ and $99 \%$ for $\mathrm{Co}$ ) with the desired ratio. The preparation was carried out in a vacuum of $1 \times 10^{-4}$ $\mathrm{Pa}$ at $1373 \mathrm{~K}$ for $3 \mathrm{~h}$. The subsequent products were milled into powders (particle size: $7.82 \mu \mathrm{m}$ ) and mounted onto an alumina substrate (Mitani Micronics Kyusyu Co., Ltd., purity: 96\%, thickness: $0.635 \mathrm{~mm}$ ) with a thicknesses of about $50 \mu \mathrm{m}$. The particle size was measured by the particle size distribution analyzer (Horiba LA-920). This step was followed by Yb-fiber laser irradiation. The mounting area on the substrate was enclosed with a polyimide-tape like an embankment, which was filled with the iron silicide powder and pressed with the glass plate. The thickness of power mounting was controlled by that of polyimidetape. The schematic diagrams of the laser irradiation experiment and the corresponding irradiation pattern are shown in Fig. 1. The powder mounting and laser irradiation were repeated between 1-3 times (I-III in Fig. 1). Briefly, the laser was focused onto the surface of iron silicide powder and the irradiation experiments were carried out under an inert Ar gas atmosphere with a CW Ybfiber laser (IPG YLR-300-SM, emission wavelength $\lambda=1070$ $\mathrm{nm}$; beam diameter $r_{B}=3.8 \mathrm{~mm}$; beam quality $M^{2}=1.1$ ). The emission beam was focused onto a spot size of $20 \mu \mathrm{m}$ through an objective lens (Sigma Koki NYDL-30-100 PY1, focal length, $f=100 \mathrm{~mm}$ ). The stage (Laserck Corp.) was scanned at a constant speed of $10 \mathrm{~mm} / \mathrm{s}$ in a lattice pattern (see inset of Fig. 1, line separation was set to $100 \mu \mathrm{m})$ and the resulting laser power $(P)$ was monitored by a power meter (Ophir FL400A-BB-50). The laser-fabricated iron silicide device was annealed at $1073 \mathrm{~K}$ for $12 \mathrm{~h}$ in a vacuum to obtain the semiconductive $\beta-\mathrm{FeSi}_{2}$ phase. The crystal structure of iron silicide layers was identified by X-ray diffraction (Rigaku RINT2500) with monochromatic $\mathrm{CuK} \alpha$ radiation. The microstructures were characterized using scanning electron microscopy (JEOL, JSM6610). 
( I)

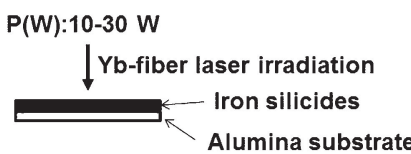

(II)

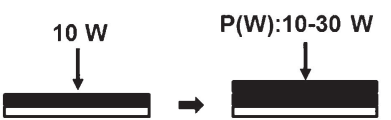

( III)

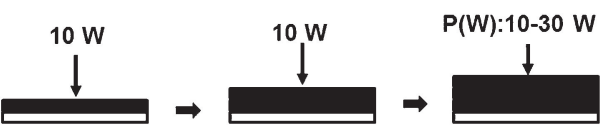

Fig. 1. Schematic diagram of the laser irradiation experiment: (I) laser power is set to $10-30 \mathrm{~W}$, (II) the first laser power is set to $10 \mathrm{~W}$ and the second to $10-30 \mathrm{~W}$, (III) the first and second powers are set to $10 \mathrm{~W}$ and the third is $10-30 \mathrm{~W}$. The irradiation pattern is shown in the inset, where route 1 is followed by route 2 displaying a lattice pattern. The thickness of iron silicide powder mounted at each step is $50 \mu \mathrm{m}$.
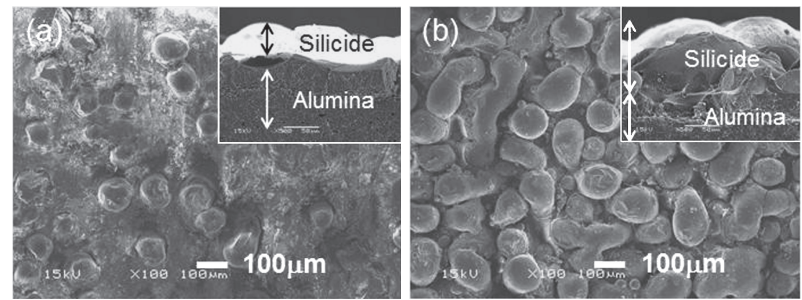

Fig. 2. SEM images of specimen surface and cross-section after laser irradiation of (a) $10 \mathrm{~W}$ and (b) $10 \mathrm{~W}-10 \mathrm{~W}$. The thickness of iron silicide powder mounted at each step is $50 \mu \mathrm{m}$. Cross-sectional SEM images are shown in the insets, where scale bar is $50 \mu \mathrm{m}$.

\section{Results and discussion}

In the first step (I) in Fig. 1, the laser power was examined in the range of $10-30 \mathrm{~W}$. The specimens were irradiated at 10,15 , 20,25 , and $30 \mathrm{~W}$ and alumina substrates were found to break into pieces at the higher power setting than $20 \mathrm{~W}$ due to thermal shock. The alumina has the heat shock resistance of about $200 \mathrm{~K}$. The irradiation conditions must be controlled the heat shock is below this value. No electrical conduction was achieved for specimens irradiated at either 10 or $15 \mathrm{~W}$. This shows poor linkage among silicide particles. Upon exposure to the laser irradiation, the iron silicide powders were found to melt and form droplet like round particles, which were approximately $100 \mu \mathrm{m}$ in size and were readily isolated from each other, as shown in Fig. 2(a). Since the absorption coefficient of $\mathrm{FeSi}_{2}$ is considerably high $\left(2 \times 10^{5} \mathrm{~cm}^{-1}\right.$ at $\left.1070 \mathrm{~nm}\right),{ }^{5), 6)}$ the penetration depth of laser into the iron silicide powders is estimated to be $5 \times 10^{-2}$ $\mu \mathrm{m}$. In this case, the laser energy was absorbed by the surface of iron silicide powders and transferred into all powder particles. Subsequently, these particles were immediately melted and aggregated onto alumina substrates to make droplet-like iron silicides. In the second step (II) in Fig. 1, the first irradiation power was fixed at $10 \mathrm{~W}$, and second power was examined from 10 to $30 \mathrm{~W}$. The specimens irradiated at high powers of 25 and $30 \mathrm{~W}$ were broken by the thermal shock. Moreover, electrical conduction was not achieved at 10,15 , and $20 \mathrm{~W}$. Although the round particles became larger in dimension and frequency, these particles were sparsely dispersed from one another, as shown in Fig. 2(b). From the cross-sectional figures in the inset of Fig. 2
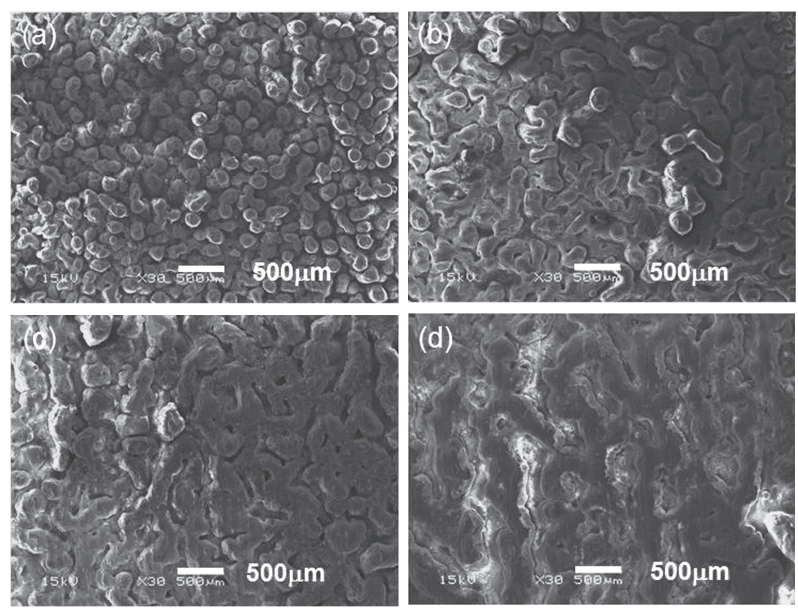

Fig. 3. SEM images of specimen surface after irradiation of $10 \mathrm{~W}-10 \mathrm{~W}-\mathrm{P}$ (W). (a) $\mathrm{P}=10 \mathrm{~W}$, (b) $15 \mathrm{~W}$, (c) $20 \mathrm{~W}$, and (d) $25 \mathrm{~W}$.
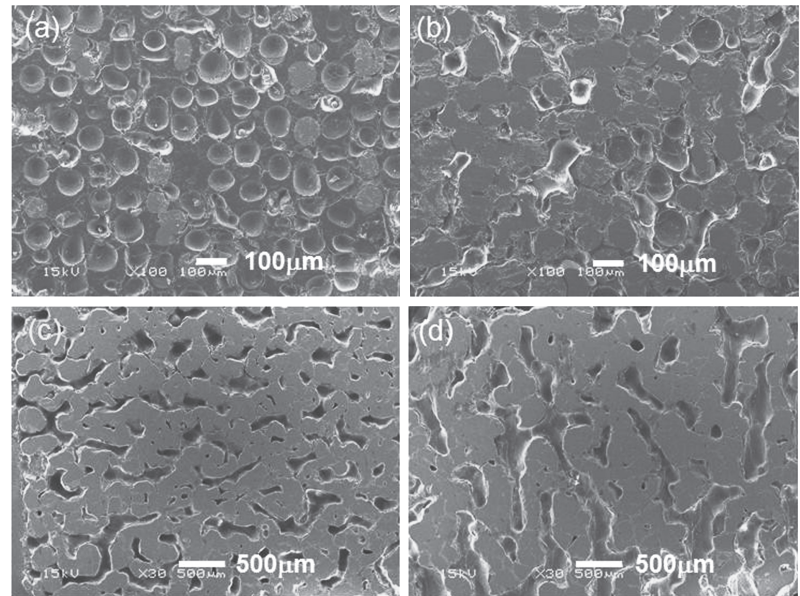

Fig. 4. SEM images of polished specimen surfaces after irradiation of $10 \mathrm{~W}-10 \mathrm{~W}-\mathrm{P}$ (W). (a) $\mathrm{P}=10 \mathrm{~W}$, (b) $15 \mathrm{~W}$, (c) $20 \mathrm{~W}$, and (d) $25 \mathrm{~W}$.

we found the surface of alumina substrates was curved and melted. In the cross-section of $10 \mathrm{~W}-10 \mathrm{~W}$ [Fig. 2(b)], there was no clear line which discriminate the silicide from alumina substrate. In the third step (III) in Fig. 1, the first and second laser power was fixed at $10 \mathrm{~W}$, and the third irradiation power was changed from 10 to $30 \mathrm{~W}$. Similarly, the specimen irradiated at $30 \mathrm{~W}$ was broken by thermal shock. The breakdown power of the substrate increased with repeating steps. This was attributed to the change in the alumina substrate position from the focal point, which was increased by about $50 \mu \mathrm{m}$ after each step. The electrical conduction over the entire sample was achieved in the irradiation process consisting of steps: (i) $10,10,20 \mathrm{~W}$, and (ii) $10,10,25 \mathrm{~W}$.

Furthermore, SEM images of the resulting surfaces obtained through the irradiation process of $10 \mathrm{~W}-10 \mathrm{~W}-\mathrm{P}(10,15,20$, $25 \mathrm{~W}$ ) and those of the polished surface are shown in Figs. 3 and 4, respectively. Here, round silicide particles with dimensions of $\sim 180 \mu \mathrm{m}$ were generated at $10 \mathrm{~W}$, and were isolated. Upon increasing the laser power, the silicide particles increased in size and were found to form a three-dimensional linkage, resulting in the electrical conduction over the entire specimen. This feature was evident as observed in the SEM images (Fig. 4). The crosssectional SEM image of the polished specimen of $10 \mathrm{~W}-10$ $\mathrm{W}-20 \mathrm{~W}$ is shown in Fig. 5. In this case, the iron silicide layer 


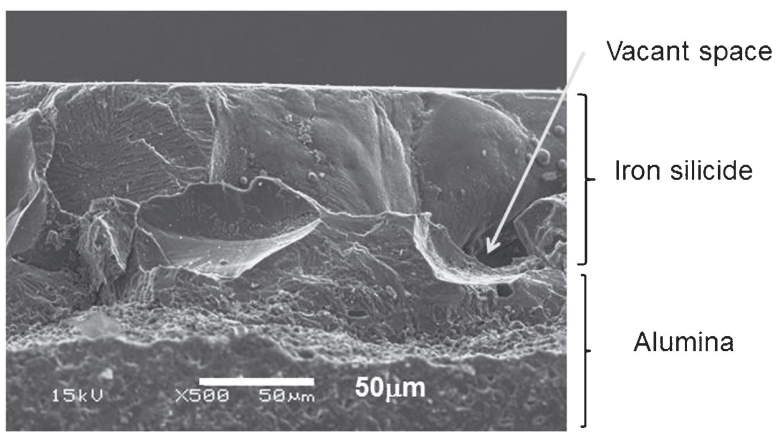

Fig. 5. Cross-sectional SEM image of the polished specimen after irradiation steps of $10 \mathrm{~W}-10 \mathrm{~W}-20 \mathrm{~W}$.

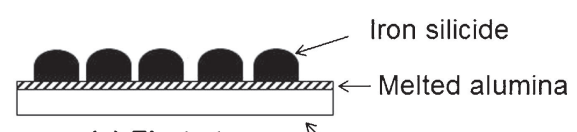

(a) First step $\nwarrow$ Alumina substrate

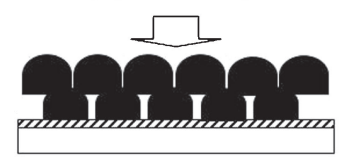

(b) Second step

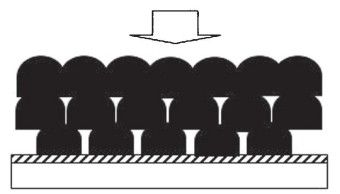

(c) Third step

Fig. 6. Laser fabrication steps for preparation of the electro-conductive iron silicide layer on an alumina substrate.

formed more robustly onto the alumina substrate. We could not find the flat surface of alumina substrate in Fig. 5. The surface of alumina was melted to a final thickness of $30-50 \mu \mathrm{m}$ as shown in Fig. 5, resulting in the formation of a rigid bond with the iron silicide layer in the first step in Fig. 1. However, a small amount of vacant space between the substrate and iron silicide layer was observed. This structure may contribute to a decrease in the thermal stress found between the alumina substrate and the iron silicide layer.

Figure 6 illustrates the three-step mechanism found in our results to fabricate an electro-conductive iron silicide layer onto an alumina substrate. Briefly, (a) round iron silicide particles are formed and are found to typically isolate from one another. Following this, (b) the size of iron silicide particles gradually increase in size. Finally, (c) the linkage between other iron silicide particles are observed to grow at laser powers of 20 and $25 \mathrm{~W}$.

XRD pattern of iron silicide layer fabricated onto alumina substrates at $10 \mathrm{~W}-10 \mathrm{~W}-20 \mathrm{~W}$ is shown in Fig. 7, along with the XRD pattern after heat treatment at $1073 \mathrm{~K}$ for $12 \mathrm{~h}$. We found that the iron silicides layer fabricated by the Yb-fiber laser was consisted of $\alpha-\mathrm{FeSi}_{2}$ and $\mathrm{FeSi}$ as shown in Fig. 7(a). The $\beta-\mathrm{FeSi}_{2}$ phase was not observed because the laser treatment was a rapidquenching process. The iron silicides on alumina substrate were converted into the semiconductive $\beta-\mathrm{FeSi}_{2}$ phase in the course of subsequent annealing at $1073 \mathrm{~K}$ in a vacuum furnace [Fig. 7(b)].

The thermoelectric power of iron disilicide device is plotted in Fig. 8. The inset depicts the image of the final thermoelectric device. The compositions of iron silicide used were $\mathrm{Fe}_{0.95} \mathrm{Mn}_{0.05^{-}}$ $\mathrm{Si}_{2}$ for p-type and $\mathrm{Fe}_{0.97} \mathrm{Co}_{0.03} \mathrm{Si}_{2}$ for n-type. The thermoelectric

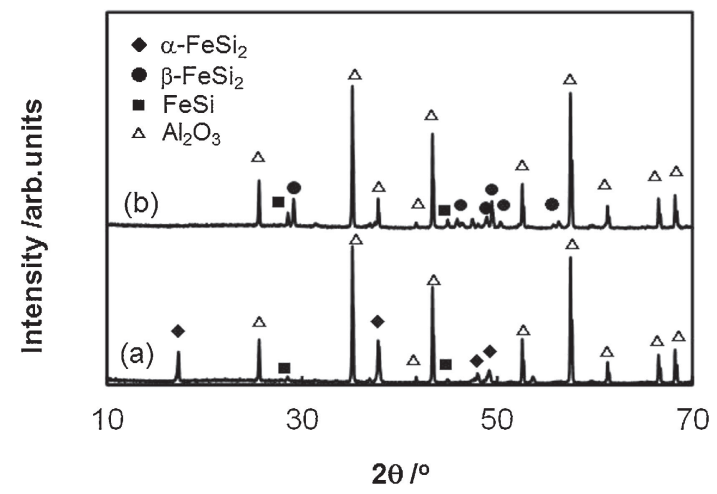

Fig. 7. XRD patterns of iron silicide layer fabricated on alumina substrates in the irradiation steps of $10 \mathrm{~W}-10 \mathrm{~W}-20 \mathrm{~W}$ (a) and after heat treatment at $1073 \mathrm{~K}$ for $12 \mathrm{~h}$ in a vacuum furnace (b).

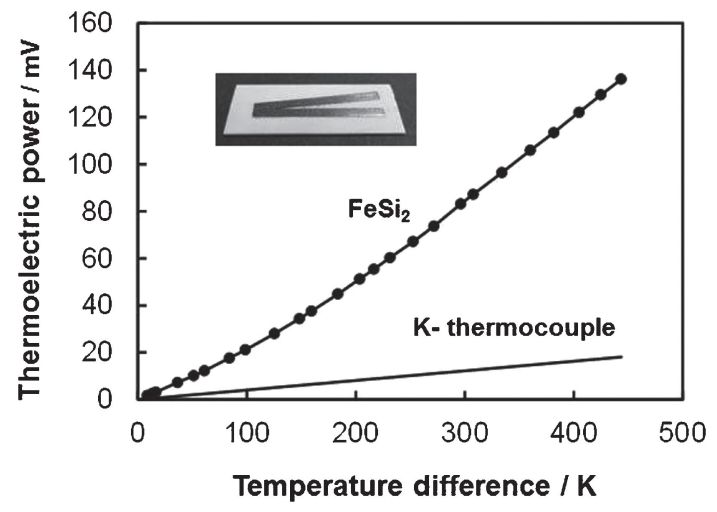

Fig. 8. Thermoelectric power of $\mathrm{FeSi}_{2}$ device along with the power of K-type thermocouple. Photograph of the device is shown in the inset.

power of the K-type thermocouple is also plotted for reference. From this, it is apparent that the thermoelectric power of the present device is significantly enhanced (seven times higher than that of K-type thermocouple) demonstrating its potential use as a temperature sensor.

\section{Conclusions}

The iron silicide thermoelectric devices were successfully fabricated by direct patterning with a continuous-wave Yb-fiber laser. The electro-conductive $\mathrm{p}-\mathrm{n}$ pattern was achieved by the multi-step irradiation process of powder mounting and irradiation. The device exhibited significantly high thermoelectric power, which was seven times larger than that of K-type thermocouple.

\section{References}

1) U. Birkholz and J. Schelm, Phys. Status Solidi, 27, 413-425 (1968).

2) I. Nishida, Phys. Rev., B7, 2710-2713 (1973).

3) T. Kojima, Phys. Status Solidi A, 111, 233-242 (1989).

4) Kubaschewski, "Binary alloy phase diagrams", vol. 2, Ed. T. B. Massalski, ASM International, Materials Park (2001) pp. 1771-1772.

5) M. C. Bost and J. E. Mahan, J. Appl. Phys., 58, 2696-2703 (1985).

6) M. Milosavljević, G. Shao, N. Bibić, C. N. McKinty, C. Jeynes and K. P. Homewood, Appl. Phys. Lett., 79, 1438-1440 (2001).

7) J. Tani and H. Kido, J. Appl. Phys., 86, 464-467 (1999).

8) J. Tani and H. Kido, J. Appl. Phys., 84, 1408-1411 (1998).

9) Y. K. Uemura and I. Nishida, "Thermoelectric Semiconductors 
and their Applications", Nikkan-Kogyo, Tokyo (1998) pp. $176-180$.

10) M. Komabayashi, K. Hijikata and S. Ido, Jpn. J. Appl. Phys., 29, 1118-1121 (1990).

11) J. Tani and H. Kido, J. Ceram. Soc. Japan, 109, 557-560 (2001).

12) H. Wu, B. Hu, N. Tian and Q. Zheng, Mater. Lett., 65, 28772879 (2011).

13) M. Pang, R. Suzuki, M. Saito, K. Machida, H. Hanzawa, Y. Nojiri and S. Tanase, J. Appl. Phys., 103, 013112 (2008).

14) T. Honma, P. T. Nguyen and T. Komatsu, J. Ceram. Soc.
Japan, 116, 1314-1318 (2008).

15) A. Bacciochini, N. Glandut and P. Lefort, J. Eur. Ceram. Soc., 29, 1507-1511 (2009).

16) M. Boutinguiza, J. del Val, A. Riveiro, F. Lusquiños, F. Quintero, R. Comesaña and J. Pou, Physics Procedia, 41, 780786 (2013).

17) H. Kido, M. Takahashi, J. Tani, N. Abe and M. Tsukamoto, Mater. Sci. Eng., 18, 072014 (2011).

18) H. Kido, M. Takahashi, J. Tani, M. Chigane, N. Abe and M. Tsukamoto, J. Ceram. Soc. Japan, 122, 21-24 (2014). 